\title{
Facades of Suffering: Clients' Photo Stories About Mental Illness
}

\author{
Jan E. Sitvast, Tineke A. Abma, and Guy A.M. Widdershoven
}

\begin{abstract}
In this article, photo stories are examined that were the result of working with photography as a therapeutic instrument dealing with suffering in mental health care settings. The purpose is to describe the role of facades in the process of suffering and acceptance. Clients took photographs, talked about them in group meetings, and exhibited them to a broader audience. Their photo stories were analyzed using a mixed-methods model. Data from two narrative approaches (semiotics and hermeneutics) were compared with information from other informants and official records to find discrepancies between the photo story and the real life context. Although facades are usually perceived as an obstacle for personal growth, the visual narratives revealed that facades can function as an alternative to common acceptance strategies, such as facing one's losses and reconciliation. Facades can create a distance between the person and the suffering. We conclude that visual narratives can reveal and foster agency in clients.

(C) 2010 Elsevier Inc. All rights reserved.
\end{abstract}

$\mathbf{L}$ IVING WITH CHRONIC illness impacts daily life and the experience of self (Charmaz, 1991; Riessman, 1990; Williams, 2001). The impact of severe mental illness is often enormous (Hinshaw, 2007); the illness disrupts the life story and necessitates an evaluation of one's identity. Suffering results to the extent one becomes aware of the losses caused by the illness. The effects related to the symptoms of mental conditions themselves may be compounded by the effects of stigmatization (Corrigan \& Watson, 2002; Hinshaw, 2007). Persons with a mental disorder often have experiences of rejection and stigmatization (Wright, Gronfein, \& Owens, 2000). This can lead to coping strategies of secrecy and social withdrawal (Corrigan, 1998; Hinshaw, 2007) or energize persons into anger about stigmatization (Corrigan \& Watson, 2002), whereas others seem indifferent to the impact of stigma altogether. Little is known about how a person with mental illness experiences life. In this study, we tried to get more understanding about how psychiatric clients endow meaning to their experiences and how they represent themselves. The study is based on photo stories made by selected mental health clients who participated in photography groups. These photography groups were guided by the principles of hermeneutic photography. Hermeneutic photography uses photographs to explore possible meanings rather than to depict an objective representation of reality (Hagedorn, 1996).

In this article, we focus on how psychiatric clients, in the context of the photography groups, give meaning to their broken lives and suffering and how facades play a role in their visual narratives.

From the GGNet, Network for Mental Healthcare in the Region Oost Gelderland, Warnsueld, The Netherlands; VU Medical Center, Amsterdam, Department of Medical Humanities, EMGO Institute, Amsterdam, The Netherlands.

Corresponding Author: Jan E. Sitvast, MA, GGNet, Kenniscentrum, Mr. Jan Sitvast, Vordenseweg 12, 7230 GC Warnsueld, The Netherlands.

E-mail addresses: j.sitvast@ggnet.nl, jsitvast@zonnet.nl (J.E. Sitvast), emgo@vumc.nl

(T.A. Abma), emgo@uumc.nl (G.A.M. Widdershoven). (C) 2010 Elsevier Inc. All rights reserved. 0883-9417/1801-0005\$34.00/0 doi:10.1016/j.apnu.2010.02.004 
The purpose of this article is to describe the role of facades in the process of suffering and acceptance.

\section{CONCEPTUAL FRAMEWORK}

\section{Suffering}

Suffering from a mental illness can be a painful struggle because what we desire or long for is often beyond our reach, for example, being free from severe mental illness. Realizing that one cannot just wish mental illness away can lead to the feeling that mental illness must be endured. One undergoes suffering rather than acting upon it (Fredriksson \& Eriksson, 2001). One can be either a "sufferer" or an "agent”(Ricoeur, 1992). Sufferers are those affected by processes in their life story. Agents, however, initiate these processes. Achieving an active relationship with suffering, in which one reshapes feelings of fear and anxiety, restores agency (Eriksson, 2006). A progressive development in suffering goes from being determined by suffering ("have" suffering) to "owning" it, but not yet acknowledging it ("be" in suffering), to confronting and assimilating it ("become" in suffering).

\section{Facades}

When people tell stories to account for disturbing events in their lives, such as the onset and progression of mental illness, they sometimes "hide" from their suffering - not mentioning it or not giving it due attention. We speak of "facades" when someone's suffering becomes invisible. Hiding from suffering is often seen as problematic because it is assumed that personal growth and development take place on the basis of acceptance of suffering (Fredriksson \& Eriksson, 2001). Acting as an agent presupposes that someone faces his suffering instead of hiding from it behind facades. Fredriksson and Lindström (2002) found that psychiatric clients used facades to hide their suffering from themselves and their social environment. The four facades they discerned are the following:

1. the alone and strong (feigning strength)

2. being a victim

3. making oneself invisible through adaptation

4. resignment.

The suffering that must be concealed from the sufferer behind these facades consists of feelings of fear, evilness, hatred, revenge, rage, and shame.
Shame, in particular, may be so intense that avoidance strategies are used as defense mechanisms against overwhelming negative feelings (Nathanson, 1992). In addition, cases have been identified in which facades were demasked by the storytellers and they themselves became part of a heroic story (Fredriksson \& Lindström, 2002). In these cases, the story begins with the denial and concealing of suffering and ends with the acceptance and confirmation of it (Lindholm \& Eriksson, 1993).

In other cases, people may hold on to facades in order to protect themselves from experiencing too much pain or suffering. If people battle against illness and the suffering it causes, "they do so for control of the defining images of self, for control over their bodies, and sometimes for control over death" (Charmaz, 1991, p. 259). This implies that one actively defends the image of self. The struggle is how to preserve self-respect. Self-respect is sustained by having control over situations and by being able to make independent choices in some domains of life, if not in all (Charmaz, 1991). These choices can hold suffering at bay, ignore or externalize it. Similarly, a facade can be freely adopted and offer an alternative to assimilating (internalizing) suffering.

\section{METHODS}

\section{Setting}

Our research studies and follows nine photography groups in three mental health institutions in the Netherlands. The aim of forming the groups was to help clients in their process of assigning meaning to their illness and experience of suffering. Comparable therapeutic interventions have been used elsewhere (Fleming, Mahoney, Carlson, \& Engebretson, 2009; Frith \& Harcourt, 2007; Hagedorn, 1996; Keller, Fleury, Perez, Ainsworth, \& Vaughan, 2008; Wang \& Burris, 1997; Weiser, 1993). Participants were invited to endow meaning to pictures made with a disposable camera. Nurses facilitated the process of elicitation among participants (see Sitvast, Abma \& Widdershoven, 2008). Elicitation means that a researcher or a therapist invites the photographers to tell what the photograph means to them. The photography groups followed a protocol developed and tested by the first author in an earlier phase of the study (Bouhuis, Middelhoven, Schoneveld, \& Sitvast, 
2003). Each photo group passes through two rounds of eight sessions. Both rounds are concluded with an exhibition in which the photo stories are shown to others. The first round focuses on what participants consider as valuable or dear to them. The second round focuses on the formulation and visualization of a wish or goal that participants would like to realize in the near future.

Settings included a (medium) long-term inpatient ward in a psychiatric hospital, a daytime treatment center, and three sheltered group homes. During 2005-2007, nine photography groups were organized (in total 42 participants). The criteria for inclusion in the study were that participants were recovering from a psychiatric crisis and that they were not severely impaired by psychiatric symptoms at the time of their participation in the photography groups.

\section{Design}

Because we wanted to gain an understanding of the role of facades, we needed to be able to compare the meanings embedded in the photo stories with the real life context of the clients. We therefore adopted a mixed-methods design in which different qualitative research methods were used for the purpose of triangulation and complementarity. By triangulation we sought convergence and corroboration of results from different methods. Complementarity served elaboration, enhancement, illustration, and clarification of the results from one method with results from the other method (Greene \& Caracelli, 2003; Onwuegbuzie \& Teddlie, 2003). To reconstruct the meanings embedded in the photo stories, two narrative traditions were integrated. To reconstruct the meanings in the photos (the visual image), a semiotic approach was followed (Riessman, 2008). Semiotics approaches meanings as sign systems; visual images are signs that can take on arbitrary meanings, depending on context (Emmison \& Smith, 2000). To interpret the meanings in the clients' stories of the photos, we used hermeneutics. Hermeneutics approaches meanings as intersubjective understandings (Hagedorn, 1996). Recently, many more examples of hermeneutic photography can be found (Frith \& Harcourt, 2007; Keller et al., 2008; Radley \& Taylor, 2003). The integration of these two narrative approaches helped to unravel various layers of meanings in the photo stories. A client might, for example, not reflect on the meaning of the split tree on a photo (hermeneutic analysis), whereas a semiotic analysis might indicate that such an image refers to a broken life.

Yet, because we were interested in the role of facades, it was necessary to relate the meanings in the photo stories to the real life context of the client. To gain such factual information, we collected additional data. Participant observation of the photo groups helped to observe the condition of the client: their verbal and cognitive skills and physical wellbeing. In addition, interviews were conducted with clients after the intervention. In addition, interviews were held with the nurses leading the photo groups to hear their view on the well-being and improvements of the clients. Official records in the form of observation forms and evaluation forms further helped to compare the story of the client with factual data. Inconsistencies between the photo story and the factual data on the life world context helped to illuminate facades. For example, a client may have high ambitions wishing to buy a Ferrari and have a bungalow, but reality might be such that a person is still hospitalized. This cross-checking between data aimed not to invalidate the clients' photo story but to discover discrepancies between the story, what the story covered up, and why such facades were used and functional for the client. A photo story of a client might factually not be true, but what was of interest to us was that it was true for the client at that moment.

\section{Data Collection}

Data consisted of photographs taken by participants and the stories that were told about them in the group sessions. Participants made up to 50 photos but eventually selected a total of 7 photographs for public exhibition: 3 from the first round and 4 photos for the second round of the photo group sessions. These photographs were the focal point of the participants' stories. Together, they formed the photo stories in a primary dataset. The researcher attended all the nine photo groups and made field notes of these participant observations. Nurses conducting the photography groups filled in an observation form to provide contextual information, for instance, on how the photo stories were received by a public. Triangulation of data was also achieved by using evaluation forms and material from a limited number of interviews with nurses conducting the photography groups and with clients. The interviews were written out verbatim. Together with the observational data, the interview 
data formed a secondary dataset. The multiple use of diverse data sets was found in comparable studies (Riessman, 2008).

\section{Analysis}

The analysis of the photographs was based on semiotics (Van Leeuwen \& Jewitt, 2001). First, we analyzed the content in terms of perspective, focus, tone, setting, and themes. Then, the symbolic meaning was unraveled looking at the images to which the photos refer (Barthes, cited by Emmison $\&$ Smith, 2000). The symbolism was understood in relation to its context, which, in turn, provided information on the function it serves for the participant.

The semiotic analysis was integrated with a hermeneutic analysis. The hermeneutic analysis focused on the verbal narrative accompanying the photographs. On this level, we analyzed what the photographer himself told about the photographs and what meaning was endowed to the photos within the intersubjective context of the photo group. Combining the verbal text with the images, we investigated how participants constructed their narrative in terms of perspective, character and plot development, and the use of metaphors. We analyzed how this narrative related to its explicit message and/or hidden functions.

To determine this relationship, we also depended on context information drawn from our observations of clients' performance in the photography groups and their comments and responses that were not integrated in the story. In addition to the message of the narrator, we thus identified hidden meanings. Facades within narratives may cover up private aspects of life, secrets, even unspeakable or illegal things (Bach, 2007; Riessman, 2008). We deliberately searched for tensions between what was expressed and these hidden meanings. In this way, a dataset was constructed for individual cases (compare: Bach, 2007). The next step was to relate the dataset with theoretical notions on suffering and facades to find a possible meta-narrative that enabled us better to see the process of meaning. Findings were again tested against data in primary datasets.

\section{Quality Criteria}

Because we wanted to find discrepancies between the story told and the life context and what and why the narrator wanted to cover up certain facts of life and suffering (the pragmatic function of the photo story), we consider our understanding as being inherently coconstructed with the narrators (Plummer, 2001). Recognizing our own positionality and subjectivity, we therefore treated our analysis as a situated interpretation (Josselson, 2006).

Following a hermeneutic perspective, we used the notion of "credibility" (Lincoln \& Guba, 1985) to ensure the validity of our study. Credibility was achieved by "prolonged engagement." We engaged in all sessions of the nine photo groups and carried out "persistent observation" during every session. Procedures to ensure credibility also included a member checking of our interpretations with the research subjects. In the member checking, we put before them our interpretation of what the images were about, what stories they were part of, and whether there were layers of meaning that we assumed to be present in a specific photo story. As far as the third aspect (the added layers of meaning) is concerned, our dataset is a composed text including theoretical notions on suffering and facades. Its nature made sharing it with participants difficult and not always possible, as the level of education of the participants varied greatly. For member check, we therefore rephrased interpretations in terms familiar to the participants. From an interpretive perspective, trustworthy interpretations are important to reach internal validity. Member checks help to validate the person's realitywhether it is understood well, not whether the story is true.

To further deepen the surface of the tale being told (visualized in photos), to reveal what remained hidden and unspoken, we took an outsider and realist position, using theoretical insights to bring these aspects to the surface. These conceptualizations enabled us to transcend the limit of what was being told/visualized. The type of validity we speak of here is the so-called explanatory (or theoretical) validity (Maxwell \& Loomis, 2003). Theoretical validity concerns the validity of claims about causal processes and relationships. In the case of our study, this can be read as: how valid are our interpretations of the processes (for instance in case of facades) with which patients give meaning to their suffering? This kind of internal validity refers to the degree to which a theoretical explanation developed by the researcher fits the data. The strategies we adopted for obtaining theoretical validity are reflexivity in a reiterant process of 
discussion between first, second, and third author; peer review; negative case analysis; and theoretical sensitivity (see also Strauss \& Corbin, 1998).

The study was executed in accordance with the norms and regulations under Dutch legislation on medical research (the WMO Law) and was approved by the appropriate medical-ethical board. A proper informed-consent procedure was part of the research protocol.

\section{FINDINGS}

In this study, we focused on (a) how psychiatric clients give meaning to their broken lives and suffering and (b) how facades play a role in their visual narratives. We will follow these two strands of analysis in the presentation of our findings. First, we will give an overall picture of all cases, then we will select cases for a more in-depth description, and we will end with an integration of findings in which suffering and facades are related to each other.

\section{Broken Lives and Suffering}

People can pass through stages of suffering. They can "have" suffering, "be" in suffering, or "become" in suffering (Eriksson, 2006). To have suffering implies that the person will not acknowledge his suffering and will flee from it, trying to explain it away. To be in suffering implies that a person often experiences restlessness and may try to alleviate his suffering through the satisfaction of direct needs. When someone becomes in suffering, someone engages in a struggle between good and evil, between hope and hopelessness, and between life and death. Passing through this struggle, the person may continue toward a higher awareness and greater spiritual strength (Eriksson, 2006).

In our study $(N=42)$, we found that in making their photo stories, 27 participants mentioned their illness and experiences explicitly and reflected on them. They can be said to be in suffering or even to become in suffering. This leaves us 15 participants who did not mention their illness experiences explicitly or only did so very briefly in their photo stories, but who focused on other aspects of their lives. Because the assignment for making photographs was about values and what one held dear, we cannot automatically say that all 15 clients have suffering, meaning that they do not experience their suffering as being part of their lives and instead feel driven and directed by external circumstances
(Eriksson, 2006). Carl, like all names a pseudonym, for instance, told how he had taken up bicycling again and how he loved it. There was no explicit mentioning of the hardships of the psychosis he had gone through, although he certainly acknowledged it on other moments than when preparing his photo story. For some other clients, it was different. They also did not mention their illness experiences or only as a passing remark, but at the same time, we then knew from other data (participant observation, observation by the nurse conducting the photo group) that these clients fled from "owning" their suffering. They can be said to have suffering. An example of this will be seen in the case study of Benny in the next paragraph.

Let us return to the larger group of clients who did mention their experiences with illness. In this group, we found ample examples of being in suffering. Judith, for instance, photographed herself with her arms raised to heaven. She told us that she wondered how she could ever become the old Judith again. She is in suffering, experiencing increased anxiety, and seeking more harmony in her life. Yet, she seems not ready to go beyond this struggle and find new meanings as ultimately happens in the phase of becoming in suffering. Susan, however, who participated in the same photo group, knew that she would never see her health restored to how it was in former times, when she was in her glory as a competitive swimmer. Yet, she photographed her preparations for a holiday trip to a Caribbean island where she hoped to go and swim with dolphins. In this way, she connected future with past experiences and reflected on them. Another example is William, who, after several sessions, openly admitted to having an alcohol addiction. Talking about his experiences with mental illness relieved the pain of isolation and alienation caused by feelings of shame. It helped to make him aware of his struggle against his addiction, which he felt as a struggle between good and evil and between hope and hopelessness. Fighting this struggle, he won back the respect of his son and in this way he found a new meaning in his suffering.

\section{Facades}

Many participants evaluated their lives and explicitly mentioned illness experiences. The evaluative direction of their photo stories could be anything from optimistic hopes for the future to not 
knowing what turn their lives would take, expectations of more stable conditions, or outright misgivings about the future. At the same time, this did not say much about the use of facades. Sometimes, facades were used in a story where its narrator in some way avoided a direct confrontation with his or her suffering, but then came to realize its true nature and used the insight for redirecting the plot of the story. In these cases, the facade that has been overcome can be a part of a progressive turn in a story plot. Ellen, for instance, at first clung to her idea that external conditions were the cause of her pain and suffering, then realized that her problems were caused by her own psychosocial functioning. She imagined that she would come out of her struggle (dark period in her life) and be happy again. Ellen put the facade aside and developed another way of coping with suffering (Sitvast et al., 2008).

Overall $(N=42)$, we found 15 cases in which we could identify a facade. Of these 15 facades, 5 dissolved where the story was further developed, thus leaving 10 stories in which the facade remained intact. Some of these stories were analyzed as a facade with which the participant shielded off painful feelings. Benny, for instance, presented himself with photographs of a glamorous life. He knew that he would be hospitalized for still some time and had to survive on a small living allowance but claimed that in the end he would overcome his problems and live in luxury. In some other cases, the storytellers neither ignored nor denied suffering but had chosen not to make it the subject of their story. These stories displayed a retreat from the struggle against one's suffering to find a temporary respite. Julia, for instance, focused on photographs of her small family: her daughter and her dog. She mentioned her loneliness and her despair but chose not to address this in her photo story. Other stories that also had stability as ultimate outcome could be sometimes characterized as "They lived happily ever after," with no clear linkage to suffering whatsoever.

Strauss (1989) describes how patients recovering from a psychiatric decompensation go through a period in which they do not take up new challenges and stay within the limited domains of their lives: the so-called wood shedding phase. This also seems to be the case here. Suffering is often so intense and prolonged that patients need a temporary escape. In the photo narratives that function as a façade, participants may tell a story about an ordinary and possible wish. Underlying disturbances cannot be included and articulated because these are too painful. The story functions as an anchor in a sea of turmoil. It helps clients to retain self-respect and not to be overwhelmed by the experiences with their illness.

\section{Three Cases}

Of the 15 cases, in which we identified a facade, 3 are presented here. First, we will describe the photo story of Pieter, which shows a progressive development and a protagonist with a strong need for control. This case contained a clear turning point and illuminates how the confrontation with reality may help the process of recovery. As such, this story illustrates the assumption in emerging theories on facades that we presented earlier on, namely, that facades need to be surpassed to overcome suffering. The second and third cases, however, function as negative cases to challenge this general insight. The second case of Judith has an undetermined ending and presents a facade that became apparent when confronting the story with the life context. The third case of Tanja, at first sight, seems to be a story with a happy ending, but after a closer look appears to be too optimistic. The three cases represent different ways in which clients handle suffering in their storytelling.

\section{Case 1: Pieter's Photo Story}

Pieter is a hospitalized 29-year-old man. He suffers from paranoid schizophrenia. He has no job, lives alone, and does not know many other people.

Semiotic Analysis. One of the photographs Pieter selected for the exhibition is of a wooded area. Pieter likens his lack of openness and impenetrability to the dense wood in the photograph: "That's me." Looking for a reason for his lack of openness, he commented to his photograph of an old mouldered elm (Figure 1), ravaged by a storm: "The tree used to be big and steadfast. Now it is sick and mouldered. It has been smashed to bits. That's what a psychosis and schizophrenia does to you."

In the second series of photo group sessions, Pieter elaborated on the theme of hope. A photograph of himself sitting on a fence portrayed him overlooking a meadow (Figure 2). The image symbolizes space and openness. He explains: "Tranquility and freedom, that is what I think of 


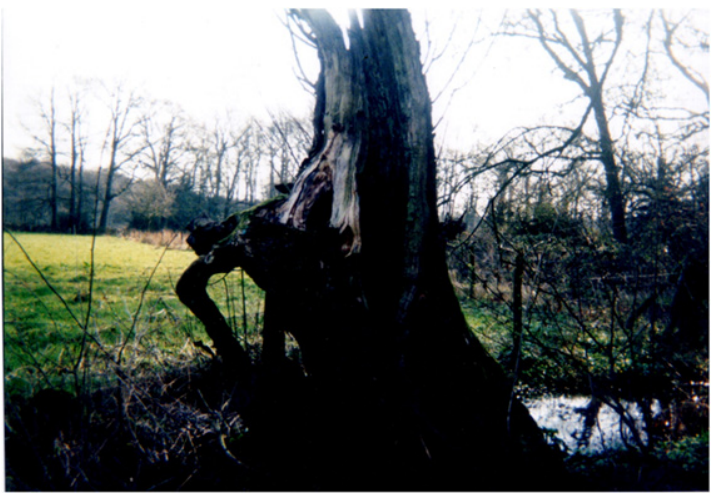

Fig 1. Pieter comparing his schizophrenia with a mouldered elm.

when I sit on a fence in a natural environment and enjoy the here and now."

A third photograph (not shown here) was taken in his room at the hospital and shows a book that has been put in the window. The book is called Catastrophobia. The Truth Behind Changes of the Earth in the Era of Light. This book symbolizes his fears. Pieter stated, "The obstacle preventing me from realizing my goals is the secret government. Through manipulation and creation of fear they want to spread their influence. But fear is only in the mind and without it they don't have power over you." A fourth photograph of caregivers and his doctor shows Pieter in the hospital setting reflecting on the support he receives from them (Figure 3).

Hermeneutic Analysis. The third photograph marks a turning point in his photo story. Pieter switches to more direct reflection and becomes more concrete and specific as to the content of his

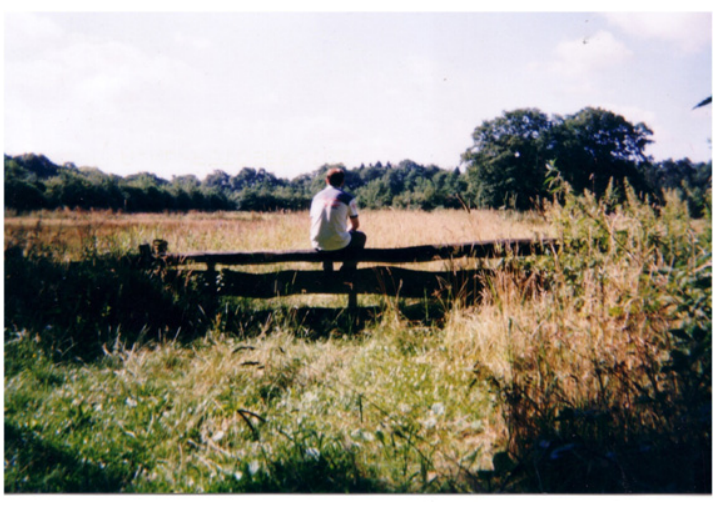

Fig 2. Pieter sitting on a fence. feelings and thoughts. There is a subtle development in the plot that shows increasing agency of the narrator. With his third photograph, Pieter comes to this conclusion: "My goal is to develop more selfconfidence and demask the plan of the secret government or to realize that this is part of my disease and that there is no secret government." In Pieter's story, facades play a transitory role. Initially, his use of imagery from nature portrayed a polished story, lacking depth and with a makebelieve quality to it. This facade protected him from premature self-disclosure. After reaching a turning point, in the second series of photo group sessions, Pieter came out from behind the shining imagery to
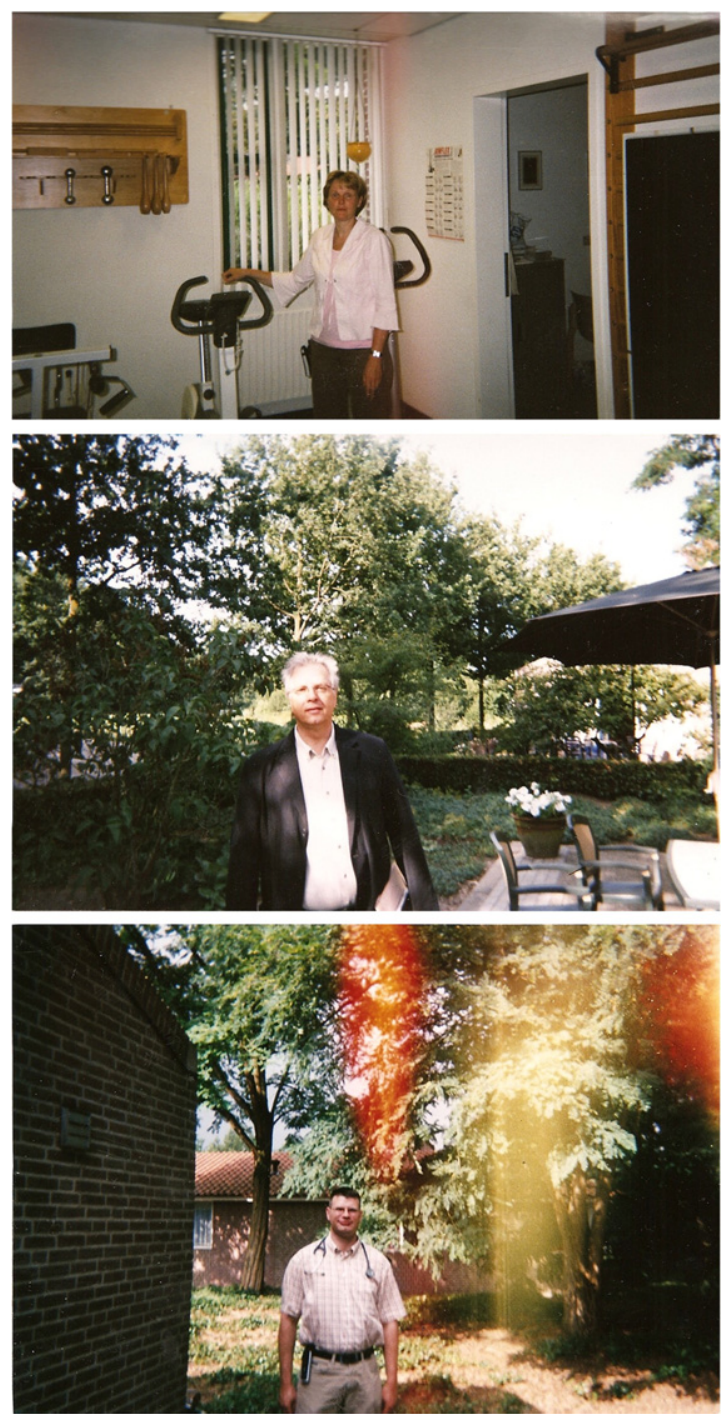

Fig 3. Pieter's caregivers and his doctor. 
tell of his delusions and raw suffering. He was able to find a way of dealing with this.

The Function of the Photo Story. Pieter benefits from his participation in the photography group in two ways: he finds meaning in his life story and at the same time he learns from this exercise in openness and connecting with others. Overcoming his reticence, he found an inner locus of control over things: medication, becoming more self-confident, and learning to master his fears. Visualizing this in strong, emotionally "dense" photographs seemed to help Pieter to anchor this insight in his consciousness. Talking about it and sharing it with others made him feel less alone. The very image that eventually stood for newly won freedom, Pieter sitting on a fence, which in itself is a metaphor for facades, also served him, at an earlier stage, to present himself as someone who is "strong but alone." The image reflects him as being inapproachable. Only through elaborating on his fears during the second series of the photo group sessions did this acquire emotional depth.

Afterword to Pieter's Story. After having participated in the photo group, Pieter went through periods of psychotic decompensation during which he was readmitted to the hospital. There were also periods of recovery. One year later, he was interviewed again. He then reported that he could cope with his fears much better. He worked three days a week and was preparing himself to live in a sheltered group home, with some other clients and with nursing guidance, as needed.

\section{Case 2: Judith Photo Story}

Judith is a 40 -year-old woman sharing a house with others and supported by rehabilitation services to maintain her in an independent living situation. At times, she suffers from psychoses. She is harassed by feelings of uncertainty and fear that hinder her in her functioning.

Semiotic Analysis. In the first series of photo group sessions, Judith made photographs that illustrated that she functioned reasonably well and that she had reached a certain psychosocial stability. In the second series of sessions, she shifts her focus to her uncertainty about how to go on from here and get better/recover: "How can I find the old Judith, I once was, before I fell ill?" One of Judith's pictures shows her with arms raised in despair (Figure 4). Judith made pictures of body

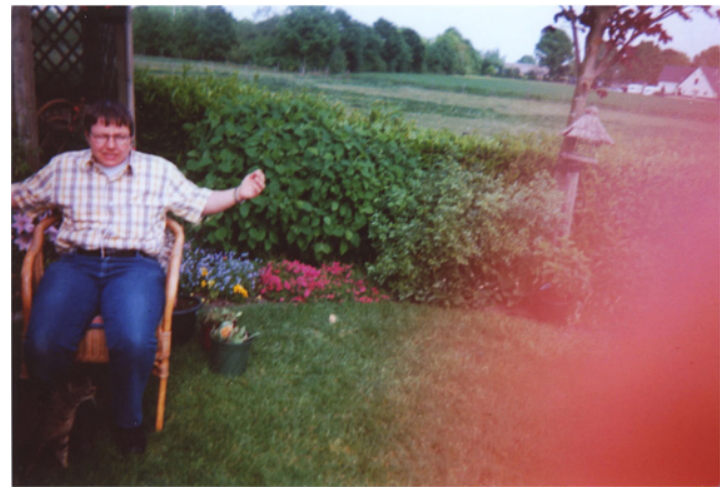

Fig 4. Judith desperately raising her arms.

language to portray herself in poses that expresses uncertainty and her wish to become more assertive.

When Judith had herself photographed in these various postures, she exposed herself to the critical gaze of spectators. This is a paradoxical unity: daring to reveal her vulnerable self and, at the same time, concealing herself behind her overt anxiety. The contrast of connecting and withdrawal was also recognized during sessions of the photo group. She often was fearful of failing in the eyes of herself and others.

Hermeneutic Analysis. The second round of the photo group sessions concentrated on what one hoped to realize in the near future. In her photo story, Judith focused on her being able to drive again and be independent from public transportation. This was brought on by an unfortunate reallife driving incident, in which Judith was arrested and had her driver's license revoked. Driving down the wrong lane is somewhat "funny," which seems to almost parallel the self-parody in her photographs. Despite the theme of hope, Judith continued the role of helpless victim in her story, with lots of irony. There was no turning point in her script.

The Function of the Photo Story. Judith confronts her anxiety by working it out in what seems a parody of helplessness, which is slightly different from the facade of being a victim. Her demonstration of helplessness may function as a protective mechanism, a strategy that aims at avoiding being held responsible for everything that might go wrong. Another possibility is that her performance evokes compassion. Helplessness does that sometimes. Perhaps this theatrical staging of her anxiety served to ease her feelings of being thwarted. 
Afterword to Judith's Story. Six months later, she and her mentor nurse were interviewed. Judith had made some progress. She had become more stable, although she still was troubled by panicky behavior at times. She had also taken up driving again. Contact with the nurses in the sheltered home had become more structured and that helped her through the day. She had not adopted a new perspective on her life. She still longed to be the old Judith again.

\section{Case 3: Tanja's Photo Story}

Tanja is a 41-year-old woman and has been a resident of a mental hospital for quite some time. The aim of her resocialization is that she resumes an independent living in her own home again. While still participating in the photo group she was dehospitalized but was soon readmitted again after accidentally using too much insulin that made her fall into a coma.

Semiotic Analysis. Tanja took photographs of a tree felled by a storm, split in two over its full length (Figure 5). Her narrative about these photographs, with such enormous, dramatic, and expressive power, was simply to say that making photographs of nature is what she loves to do as a hobby: "Making photographs of natural scenery gives me peace and relaxes me." In her photo essay, she focused on a future in which she would make fine

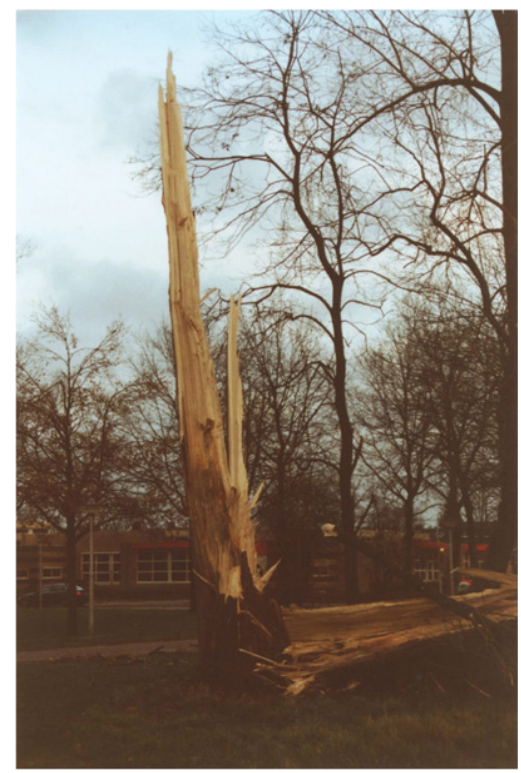

Fig 5. Tanja's tree split by lightning. pictures with a semiprofessional camera that she hoped to own. At that time, Tanja was due to be discharged from the hospital in the near future and live on her own again after a long hospitalization. On the one hand, this was what she eagerly wanted. On the other hand, she dreaded the idea that she had to be responsible for herself. She was torn between these two feeling and yet she could not show this in her photographs because that would bring it out in the open. The storm-felled tree begged for a more symbolic significance and might have been an opening to acknowledge the tensions Tanja felt. Tanja cherished being a photographer because it connected her with a past in which her grandfather had won prizes as an amateur photographer and a present in which photographs play an important role in keeping alive the memories of holidays spent with family in South Africa. After a troubled period of hospitalization, she now imagines living her life at home, in harmony with herself, and making fine pictures of nature.

Hermeneutic Analysis. Tanja's story reads like a comedy, a type of story with a happy ending after earlier setbacks and suffering but with no great control over events on the part of the protagonist (Wiklund, Lindholm, \& Lindström, 2002; Wiklund, Lindström, \& Lindholm, 2006). Based on contextual knowledge, we may doubt whether the image of stability in Tanja's story is realistic. Tanja became an outpatient during the last sessions of the second round of the photography group but was soon rehospitalized again after an insulin-related coma at home. Tanja's story is a facade, her facade. It focuses on a carefree hobby, a family tradition. Troublesome circumstances that complicated her life were only shared "off the record." There was no integration of those into her photo narrative; it reads like a "they lived happily ever after" story. Tanja is ignoring her suffering. The facade is one in which the protagonist makes her suffering invisible. Tanja seems to have withdrawn from her suffering to find a temporary respite. This is in itself an aspect of tragedy (Wiklund et al., 2002, 2006).

The Function of the Photo Story. Tanja preferred to focus on the photograph of a semiprofessional camera versus the split tree. This picture symbolized something important to her, a purpose in life to strive for. If her story focuses on goals that are not feasible right now, they may still function as a beacon in future toward which all her efforts can be directed. Almost more important than how 
things work out or how realistic her plans are is that her story serves to validate the image she clings to as a representation of her "real" self and in this way helps her to "woodshed" her integrity (Strauss, 1989).

Clearly, there are various ways facades can help people overcome suffering and vulnerability. In Pieter's case, a turning point dissolved the facade. As Tanja's case showed us, the facade can be ambiguous, repressing the suffering, but can remain intact and act as a beacon for the future. Ultimately, the image of being a photographer may increase her awareness of her own strength, which, in turn, may enable her to face her vulnerability.

Afterword to Tanja' story. Tanja did not recover fully from the neurological damage caused by the coma. She will probably never be able to live on her own again. Yet, true to her wish to make fine photographs, she eventually bought the camera that she had mentioned in the photo group sessions.

\section{Integration}

There are stages of suffering in which persons move to and fro between suffering and desire and between hope and hopelessness. Transformation or becoming in suffering (Eriksson, 2006) is achieved through confronting suffering and engaging in struggle. This, our study indicates, is often too intense and high pitched for clients who suffer or have suffered from severe, long-term mental illness. With the exception of Pieter's, the cases we studied show that there are other forms of meaning making that do not entail a direct confrontation but deal with suffering nonetheless, albeit in a more roundabout way. In the case of Pieter, there was a direct reflection on the sources of his suffering and a struggle to overcome his suffering. The facade of being strong and successful was dissolved; Pieter faced his vulnerability. He can be seen as "becoming in suffering."

In Judith's story, her life and story seem to coincide. She seems to lament her situation and expresses this more with how she performs her story than with the words she uses. Just as Tanja, she tackles her suffering, but in an indirect manner, circling around suffering, avoiding a direct head-on confrontation with it. Yet, the irony of her comments on her situation opens perspectives for developing a relationship with her suffering.

The case of Tanja is more problematic. One might say that she is not in her suffering but can stand besides it; she is with her suffering. She makes her suffering invisible through a facade; she disregards the gloomy prospects for the future and cherishes the image of becoming an artist. She prefers her photograph of a camera, embodying her created self-image, instead of the split tree. She did not opt for confronting reality by using the possible metaphoric meaning of the split tree and tell us about her dilemma of choosing for a life outside the hospital with full responsibility or continuing in the safe institutional environment.

The visual narratives of Judith and Tanja indicate that instead of assimilating one's suffering, one can step out of it and create a distance between oneself and one's suffering. In the face of suffering, one can cling to a sheltered and cocooned perception of one's self and life story or find refuge in living in the present (Charmaz, 1991). One may argue that these responses are forms of facades and that these facades can be highly functional. Living in the here and now and just taking life's troubles and joys bit for bit, moment for moment, may be a survival strategy to help someone to cope. Another route that one can take is the flight forward into the future, staking everything on the hope that one day life will turn out fine and one can live fully and happily as is longed for and wished for deep inside. Is this not what Tanja's story is about? Clinging to images of "valued" life may be more useful to restore or maintain dignity than a direct confrontation with the sources of suffering. Making suffering invisible through a facade, as Tanja did, can be interpreted as a positive effort to circumvent and go around her suffering and to connect again with a life still worth living. This may be a better strategy for clients who are already immersed in a severe, chronic mental illness.

Fredriksson and Eriksson (2001) view the distance that suffering creates between the person and his life as a gap that must be closed to achieve a new wholeness. The cases we studied demonstrate that for some severe psychiatrically disabled people, the opposite may be true. The distance that they placed between themselves and their suffering is a space that facilitated a feeling of control. This feeling of control may have been less effectively obtained with assimilation and integration of suffering. The distancing from suffering can also be considered a form of transcendence of illness and suffering because it accepts them as facts 
of life that cannot be changed. Confronting illness, in this sense, would be perhaps "more expensive" in terms of spending time and energy on this, considering possible relapses and the occurrence of "bad days" (Charmaz, 1991).

\section{DISCUSSION}

\section{Suffering and Identity}

Much of the literature on suffering departs from the assumption that only a direct confrontation with and assimilation of the sources of suffering can help people to overcome or transcend their suffering. Our study found that persons suffering from severe mental illness can circumvent their suffering in representations of themselves that do not fit a linear development to more acceptance or assimilation of (suffering from) mental illness.

This seems to confirm what Veer van 't, Kraan, Drosseart, and Modde (2006) found when they investigated stigmatization processes of the mentally ill in the Netherlands: There is an important difference between an established identity and an accepted identity as a "mental patient." In their study, most people had established identities as a patient, but only a small percentage had also accepted it in terms of attributing stigma internally. The three cases we analyzed show that all three clients were fully aware of their being a mental patient, but also that their stories reflected this in diverse ways. Pieter attributed his impaired cognitive and social functioning to his schizophrenia but did not accept it. Judith knew she was not like the old Judith and lamented it. Tanja chose to "forego" her being a mental patient: Her representation was her identity "beyond" being a patient. She seemed to be indifferent to the implications of her being a mental patient.

\section{Resilience and Strength}

What we observe here is not the loss of identity that was found in a recent study by John Fleming et al. (2009) in which mental illness experiences expressed in a photovoice project were examined. Neither can we speak of a focus, as Fleming found, on the negative aspects of the mental illness experience, although Judith's story comes close to it. Overall, 30 of 42 photo stories from our research had a positive orientation and bear witness to resilience and strength rather than to despair and strong externally navigated experiences of stigma.
We think that this discrepancy with Fleming's findings can be explained by the fact that clients in our study were asked what they valued in life rather than what mental illness meant to them. In addition, they went through a process of refining/repeating their narratives, which is distinctly different from a one-time rendering of their story. The process of showing photographs and telling one's story in the context of group sessions with fellow clients does develop the narratives and contributes to more insights into their feelings beyond a more typical account of the condition of suffering from a mental disorder. This would confirm the transformative power that is realized through narratives (Frank, 1995; Hagedorn, 1996; Lieblich, McAdams, \& Josselson, 2004; Plummer, 2001).

\section{Implications for Research}

The investigated cases show that categorizations in terms of facades are inadequate to encompass the richness and density with which a story reflects a person's life and the difficult circumstances that shape it. Much more research into personal narratives is required to enrich our understanding of personal representations of people suffering from mental illness. The role that internal and external attribution plays in these narratives deserves special attention but is too narrow to realize a broader understanding of the potential of these stories to reassert meaning to a disrupted life. Stigma and stigmatization pose another research agenda that can build on insights from such research as outlined above.

\section{Implications for Practice}

We have shown how visual narratives can help to gain a deeper understanding of suffering as experienced by psychiatric clients. Photographs and the significance endowed to the pictures by the makers reveal meanings, including emotions and feelings, which are generally not tapped in an interview situation. Psychiatric clients are often very cryptic in interview settings. Question-andanswer interviews are often experienced as examinations and do not always produce meaningful data (Abma, 1998). Therefore, Mertens (2002) pleads for more flexible and creative methods to be able to reach and include marginalized groups. Giving people a camera and inviting them to comment on pictures is less objectifying. Photography, as a medium, is attractive because much can be said 
nonverbally; what cannot be expressed in language can be expressed visually. Imagery, like poetry, creates more room for the inexpressible and unspeakable experiences. Where these experiences find expression in facades it can be relevant for caregivers to discern the various forms that facades can take and what function they serve in protecting clients from a loss of identity. At the same time, it is important for caregivers to be aware that the use of facades does not necessarily preclude a transformation of someone's narrative and may even be one of its stages. This insight helps them to avoid the pitfall of static thinking that always threatens professionals who are used to working with diagnostic labels. It may sensitize caregivers to a more dynamic and diachronic perspective on traumatic experiences of mental illness and, in this way, contribute to less unilinear and more narrative models of nursing (Sitvast, 2009; Brockmeier, 2000). This means that instead of stimulating someone to confront his suffering, it may be better to be truly present, carefully listen, and "receive" a story. In this way, caregivers can facilitate the process of meaning-giving by inviting the client to reflect on past experiences based on current needs yet also look forward to the promise of the future.

\section{CONCLUSIONS}

Many photo stories in our study reflect the strength of clients, but this does not necessarily mean they seek a confrontation with sources of suffering. Facades can fulfill useful, sometimes transitory, roles. They protect the storyteller from too direct a confrontation with their suffering. Facades are sometimes an intermediary step in a development in which one learns to face suffering more directly, but they can also offer an alternative to confrontation. Although Pieter is able to give his pain and suffering a place and gives up his facade, Judith and Tanja actually use facades to cope with their suffering, creating a distance through irony or a flight into the future. Cases like those of Tanja and Judith show that facades can contain indirect ways of tackling suffering that need not be based on rationalized verbal responses. Their rich accounts cast doubt on the received theory and throw light on future directions for theoretical research on suffering and the role of facades. Of course, rejection of a theory based on two stories is extreme, yet it may lead to a revision of the theory or return to larger samples. Visual narratives compared with the real-life context can reveal the hidden experiences of suffering and help to understand the pragmatic role of facades in the lives of the severe mentally ill. As part of a mixedmethods model of inquiry, they offer a fruitful and appropriate approach for the understanding of psychiatric clients. Moreover, the opportunity to tell their story offers clients a creative format and process to take on new roles and come to grips with their lives and suffering.

\section{REFERENCES}

Abma, T. A. (1998). Storytelling as inquiry in a mental hospital. Qualitative Health Research, 8(6), 821-838.

Bach, H. (2007). Composing a visual narrative inquiry. In D. J. Clandinin (Ed.), Handbook of narrative inquiry. Thousand Oaks: Sage Publication.

Bouhuis A., Middelhoven C., Schoneveld T., \& Sitvast, J. E., (2003). Fotografie als interventie. Een actieonderzoek in de psychiatrie, (a research report commissioned by Opleiding GGZ-Verpleegkundig Specialist in Utrecht). Utrecht (The Netherlands), unpublished.

Brockmeier, J. (2000). Autobiographical time. Narrative Inquiry, 10(1), 51-73.

Charmaz, K. (1991). Good days, bad days. the self in chronic illness and time. New Brunswick: Rutgers University Press.

Corrigan, P. W. (1998). The impact of stigma on severe mental illness. Cognitive and Behavioural Practice, 5, 201-222.

Corrigan, P. W., \& Watson, A. C. (2002). The paradox of selfstigma and mental illness. American Psychological Association, D12, 35-53.

Emmison, M., \& Smith, P. (2000). Researching the visual. London: Sage Publications.

Eriksson, K. (2006). The suffering human being. Chicago: Nordic Studies Press (translated from swedish by Olsson K.A. \& Peterson C.I.; original title Den Lidande Människan).

Fleming, J., Mahoney, J., Carlson, E., \& Engebretson, J. (2009). An etnographic approach to interpreting a mental illness photovoice exhibit. Archives of Psychiatric Nursing, 23 (1), 16-24.

Frank, A. W. (1995). The wounded storyteller. Chicago: University of Chicago Press.

Fredriksson, L., \& Eriksson, K. (2001). The patient's narrative of suffering: A path to health? An interpretative research synthesis on narrative understanding. Scand J Caring, $15,3-11$.

Fredriksson, L., \& Lindström, U. A. (2002). Caring conversations-Psychiatric patients' narratives about suffering. Journal of Advanced Nursing, 40(4), 396-404.

Frith, H., \& Harcourt, D. (2007). Using photography to capture women's experiences of chemotherapy: Reflecting on the method. Qualitative Health Research, 17(10), $1340-1350$ 
Greene, J. C., \& Caracelli, V. J. (2003). Making paradigmatic sense of mixed methods practice. In A. Tashakkori \& C. Teddlie (Eds.), Handbook of mixed methods in social \& behavioral research. Thousand Oaks: Sage Publications.

Hagedorn, M. I. (1996). Photography: An aesthetic technique for nursing inquiry. Issues in Mental Health Nursing, 17, 517-527.

Hinshaw, S. P. (2007). The mark of shame. Stigma of mental illness and an agenda for change. New York: Oxford University Press.

Josselson, R. (2006). Narrative research and the challenge of accumulating knowledge. Narrative Inquiry, 16, 3-10.

Keller, C., Fleury, J., Perez, A., Ainsworth, B., \& Vaughan, L. (2008). Using visual methods to uncover context. Qualitative Health Research, 18(3), 428-436.

Leeuwen, van T. \& Jewitt, C. (Eds.). (2001), Handbook of visual analysis. London: Sage Publications.

Lieblich, A., McAdams, D. P., \& Josselson, R. (2004). Healing plots. The narrative basis of psychotherapy. Washington: American Psychological Association.

Lincoln, Y. S., \& Guba, E. G. (1985). Naturalistic inquiry. London: Sage Publications.

Lindholm, L., \& Eriksson, K. (1993). To understand and alleviate suffering in a caring culture. Journal of Advanced Nursing, 18, 1354-1361.

Maxwell, J. A., \& Loomis, D. M. (2003). Mixed methods design: An alternative approach. In A. Tashakkori \& C. Teddlie (Eds.), Handbook of mixed methods in social \& behavioral research. Thousand Oaks: Sage Publications.

Mertens, D. (2002). The evaluator's role in the transformative context. In K. E. Ryan \& T. S. Schwandt (Eds.), Exploring evaluator role and identity (pp. 103-118). Greenwich, CT: IAP.

Nathanson, D. L. (1992). Shame and pride. Affect, sex, and the birth of the self. New York/London: Norton \& Company.

Onwuegbuzie, A. J., \& Teddlie, C. (2003). A framework for analyzing data in mixed methods research. In A. Tashakkori \& C. Teddlie (Eds.), Handbook of mixed methods in social \& behavioral research. Thousand Oaks: Sage Publications.

Plummer, K. (2001). Documents of life 2. An invitation to a critical humanism. London: Sage.

Radley, A., \& Taylor, D. (2003). Images of recovery: A photoelicitation study on the hospital ward. Qualitative Health Research, 13(1), 77-99.
Ricoeur, P. (1992). Oneself as another. Chicago: The University of Chicago Press (transl. from french by Blamey K. ; original title : Soimême, comme un autre).

Riessman, C. K. (1990). Strategic uses of narrative in the presentation of self and illness: A research note. Soc Sci Med, 30(11), 1195-1200.

Riessman, C. K. (2008). Narrative methods for the human sciences. Thousand Oaks: Sage Publications.

Sitvast, J. E., Abma, T. A., \& Widdershoven, G. A. M. (2008). Photo stories, Ricoeur, and Experiences From Practice. A Hermeneutic Dialogue. Advances in Nursing Science, 31 (3), 268-279.

Sitvast, J. E. (2009, May). Een narratief model voor de zieke mens (a narrative model for ill persons). Tijdschrift voor Ziekenverpleging (TvZ), 119(5), 24-27.

Strauss, A., \& Corbin, J. (1998). Basics of qualitative research: Techniques and procedures for developing grounded theory. Thousand Oaks, CA: Sage.

Strauss, J. S. (1989). Subjective experiences of schizophrenia Ts Schizophrenia Bulletin, Vol. 15.

Veer van 't, J. T. B., Kraan, H. F., Drosseart, S. H. C., \& Modde, J. (2006). Determinants that shape public attitudes towards the mentally ill. A Dutch public study. $S o c$ Psychiatry Psychiatr Epidemiol, 41, 310-317.

Wang, C., \& Burris, M. A. (1997). Photovoice: Concept, methodology, and use for participatory needs assessment. Health Education \& Behaviour, 24(3), 369-387.

Weiser, J. (1993). Phototherapy techniques. Exploring the secrets of personal snapshots and family albums. San Francisco: Jossey-Bass Publishers.

Wiklund, L., Lindholm, L., \& Lindström, U. A. (2002). Hermeneutics and narration: A way to deal with qualitative data. Nursing Inquiry, 9(2), 2-12.

Wiklund, L., Lindström, U. A., \& Lindholm, L. (2006). Suffering in addiction-A struggle with life. Theoria, Journal of Nursing Theory, 15(2), 7-16.

Williams, G. (2001). The genesis of chronic illness: Narrative reconstruction. In L. P. Hinchman \& S. K. Hinchman (Eds.), Memory, identity, community. The idea of narrative in the human sciences (pp. 185-211). Albany: State of New York Press.

Wright, E. A., Gronfein, W. P., \& Owens, T. J. (2000). Deinstitutionalization, social rejection, and the selfesteem of former mental patients. Journal of Health and Social Behavior, 41, 68-90. 